\title{
Clinical significance of immunohistochemical expression of insulin-like growth factor-1 receptor and matrix metalloproteinase-7 in resected non-small cell lung cancer
}

\author{
TAKETSUGU YAMAMOTO ${ }^{1}$, TAKASHI OSHIMA ${ }^{2}$, KAZUE YOSHIHARA $^{2}$, TEPPEI NISHI $^{3}$, HIROMASA ARAI $^{3}$, \\ KENJI INUI $^{3}$, TAKESHI KANEKO ${ }^{3}$, AKINORI NOZAWA ${ }^{4}$, HIROYUKI ADACHI ${ }^{1}$, \\ YASUSHI RINO $^{1}$, MUNETAKA MASUDA ${ }^{1}$ and TOSHIO IMADA ${ }^{1}$ \\ ${ }^{1}$ Department of Surgery, Yokohama City University, Yokohama-city, Kanagawa 236-0004; \\ ${ }^{2}$ Gastroenterological Center; ${ }^{3}$ Respiratory Center; ${ }^{4}$ Department of Pathology, \\ Yokohama City University Medical Center, Yokohama-city, Kanagawa 232-0024, Japan
}

Received December 13, 2011; Accepted January 30, 2012

DOI: $10.3892 / \mathrm{etm} .2012 .493$

\begin{abstract}
Insulin-like growth factor-1 receptor (IGF-1R) and matrix metalloproteinase-7 (MMP-7) have been reported to be related to tumor invasion and metastasis in various malignancies. The aim of this study was to evaluate the expression levels of IGF-1R and MMP-7 in resected non-small cell lung cancer (NSCLC) and to examine the relationship of such levels to clinical characteristics and survival. Expression was measured immunohistochemically. The percentage of stained cells was multiplied by the staining intensity. The sample was classified as high when the score was equal or higher than the median value or was otherwise considered to be low. High IGF-1R expression was associated with nodal metastasis and recurrence $(\mathrm{P}=0.034$ and 0.006 , respectively). High IGF-1R expression was associated with significantly poorer overall survival than low IGF-1R expression $(\mathrm{P}=0.011)$. MMP-7 expression did not significantly correlate with any clinicopathological factor. There was a trend toward slightly, but not significantly poorer survival in patients with MMP-7high tumors than in those with MMP-7-low tumors $(\mathrm{P}=0.220)$. There was no significant correlation between IGF-1R expression and MMP-7 expression $(\mathrm{P}=0.184)$. Upon multivariate analysis, IGF-1R expression was independently related to the outcomes of patients with NSCLC. Overexpression of IGF-1R may be a useful predictor of lymph node metastasis, recurrence and post-surgical outcomes in patients with NSCLC.
\end{abstract}

Correspondence to: Dr Takashi Oshima, Gastroenterological Center, Yokohama City University Medical Center, 4-57 Urafune-cho, Minami-ku, Yokohama-city, Kanagawa 232-0024, Japan

E-mail: ohshimatakashi@yahoo.co.jp

Key words: insulin-like growth factor-1 receptor, matrix metalloproteinase-7, non-small cell lung cancer

\section{Introduction}

Primary lung cancer is one of the most common types of cancer worldwide, and non-small cell lung cancers (NSCLCs) account for approximately $85 \%$ of all primary lung cancers. Surgical resection is the only potentially curative treatment for patients with early disease. However, the 5-year survival rate after surgical resection remains unsatisfactory. Improved survival of patients with NSCLC requires better clinical predictors of outcomes and of response to specific therapeutic interventions.

Insulin-like growth factor-1 receptor (IGF-1R) is a transmembrane heterotetrametric protein encoded by the $I G F-1 R$ gene located on chromosome 15q25-q26. IGF-1R promotes oncogenic transformation, growth and survival of cancer cells (1-4). The binding of insulin-like growth factor (IGF)-1 and IGF-2 to the extracellular subunit domain of IGF-1R activates the tyrosine kinase activity of IGF-1R and triggers a cascade of reactions involving signal transduction pathways, including components such as Ras, Raf, mitogen-activated protein kinase and phosphoinositol-3-kinase (PI3K)/AKT/BAD (Bcl-xL/Bcl2-associated death promoter) (5). IGFs are synthesized together with six molecular species of specific binding proteins [IGF binding protein (IGFBP)-1 to -6]. IGFBPs modulate IGF-1 and IGF-2 bioavailability in both circulation and the cellular microenvironment. In several malignancies, IGF-1R overexpression promotes tumor growth, progression, invasion and metastasis (6). Increased metastatic activity was reported in mice after intrasplenic injection of lung cancer cell lines transfected with IGF-1R (7).

Matrix metalloproteinases (MMPs) are a family of highly conserved enzymes that are capable of degrading the extracellular matrix (ECM). Over 25 well-characterized members of this proteinase family have been identified. MMPs play key roles not only in normal processes, but also in tissue remodeling associated with inflammatory disease, cancer invasion and metastasis $(8,9)$. Substantial evidence indicates that overexpression of MMPs correlates with a more aggressive tumor-cell phenotype, as well as with poor outcomes in patients with cancer. 
MMP-7 is the smallest (28 kDa) member of the MMP family. It has broad substrate specificity against ECM components and is produced by tumor cells. The functions of MMP-7 include destruction of basement membrane components, which is a crucial event in tumor cell invasion and metastasis. Increased expression of MMP-7 in cancer cells is associated with tumor progression and metastasis in various types of cancer $(10,11)$. To date, few studies have examined the expression of MMP-7 in lung cancer (12-14).

Miyamoto et al (15) reported that MMP-7 possesses IGFBP-3 protease activity. MMP-7-induced proteolysis of IGFBP-3 plays a crucial role in regulating IGF-I bioavailability and promotes cell survival. These findings suggest that MMP-7 may augment carcinogenesis and the progression of tumors that express IGF-1R. Adachi et al (16) found that IGF/IGF-1R upregulated MMP-7 expression in a gastrointestinal cancer cell line, suggesting that a positive feedback loop involving IGF-1R and MMP-7 may have a part in tumor progression.

The aim of this study was to evaluate the expression levels of IGF-1R and MMP-7 in resected NSCLC, and to examine the relations of such levels to clinical characteristics and survival.

\section{Patients and methods}

Patients. This study was performed in 78 consecutive patients with pathological (p)-stage I to III NSCLC who underwent complete tumor resection and nodal dissection without any pre-operative therapy at the Respiratory Center, Yokohama City University Medical Center, between January 1, 2000 and November 30, 2003.

The subjects were 54 men and 24 women with a mean age of 64.7 years (range 19-82; median 65) (Table I). The most common histological type of tumor was adenocarcinoma (57.7\%; 45 cases), followed by squamous cell carcinoma (33.3\%; 26 cases), large-cell carcinoma $(6.4 \% ; 5$ cases), typical carcinoid (1 case) and pulmonary blastoma ( 1 case). The stage of the primary tumor was $\mathrm{T} 1$ in 35 patients $(44.9 \%)$, $\mathrm{T} 2$ in 29 (37.1\%), T3 in 9 (11.5\%) and T4 in 5 (6.4\%). Thirty-eight (48.7\%) patients had no metastasis to regional lymph nodes (N0), whereas $11(14.1 \%)$ had metastatic involvement of the hilar lymph nodes (N1), and 29 (37.1\%) had metastases to the mediastinal nodes $(\mathrm{N} 2, \mathrm{~N} 3)$. Thirty-two tumors $(41.0 \%)$ were classified as stage I, $15(19.2 \%)$ were stage II and 31 (39.7\%) were stage III. At the end of follow-up, 36 patients (46.1\%) were alive and $42(53.8 \%)$ had died.

Histological subgroups were determined according to the World Health Organization classification. Pathological tumornode-metastasis classification and staging were assigned in accordance with the International Staging System. The mean follow-up was 1,466 days (range 106-3,328). Informed consent was obtained from each patient and the Yokohama City Medical Committee approved this study.

Immunohistochemistry. Formalin-fixed, paraffin-embedded tissue specimens were cut into $4-\mu \mathrm{m}$ thick sections and mounted on slides. The sections were deparaffinized and rehydrated.

For IGF-1R, the slides were heated in a microwave for $10 \mathrm{~min}$ in a $10-\mu \mathrm{mol} / 1$ citrate buffer solution at $\mathrm{pH} 6.0$ and cooled to room temperature for $20 \mathrm{~min}$. After quenching
Table I. Patient characteristics.

\begin{tabular}{lc}
\hline Characteristics & No. of patients $(\%)$ \\
\hline Total & $78(100)$ \\
Age (mean \pm SD), years & $64.7 \pm 10.8$ \\
Gender & \\
Male & $54(69.2)$ \\
Female & $24(30.7)$ \\
Histological type & \\
Adenocarcinoma & $45(57.7)$ \\
Squamous cell carcinoma & $26(33.3)$ \\
Large-cell carcinoma & $5(6.4)$ \\
Typical carcinoid & $1(1.3)$ \\
Pulmonary blastoma & $1(1.3)$ \\
Pathological stage & \\
I & $32(41.0)$ \\
II & $15(19.2)$ \\
III & $31(39.7)$ \\
Smoking status & \\
Smoker & $56(71.8)$ \\
Non-smoker & $22(28.2)$ \\
T-factor & \\
T1 & $35(44.9)$ \\
T2 & $29(37.2)$ \\
T3 & $9(11.5)$ \\
T4 & $5(6.4)$ \\
N-factor & \\
N0 & $38(48.7)$ \\
N1 & $11(14.1)$ \\
N2 & $28(35.9)$ \\
N3 & $1(1.3)$ \\
Recurrence & \\
$(+)$ & $36(46.2)$ \\
$(-)$ & $42(53.8)$ \\
\hline &
\end{tabular}

the endogenous peroxidase activity with $3 \% \mathrm{H}_{2} \mathrm{O}_{2}$ for $5 \mathrm{~min}$, the sections were incubated for $60 \mathrm{~min}$ at room temperature with the primary antibody diluted at 1:100 for IGF-1R (a rabbit polyclonal antibody, clone 1161; Signalway Antibody, Pearland, TX, USA). Peroxidase-Labeled Polymer EnVision+ kit (Dako, Glostrup, Denmark) was used for specific staining.

For MMP-7, after the endogenous peroxidase activity was blocked, the sections were incubated for $90 \mathrm{~min}$ at room temperature with the primary antibody for MMP-7 (a mouse monoclonal antibody, clone 141-7B2; Daiichi Fine Chemicals, Toyama, Japan), diluted at $20 \mu \mathrm{g} / \mathrm{ml}$. Endogenous biotin was blocked by Dako's Biotin Blocking system (Dako), according to the manufacturer's specifications. After rinsing, specific staining was visualized with the use of an LSAB+ systemHRP system (Dako).

Color was produced by the application of 3,3'-diaminobenzidine for $10 \mathrm{~min}$. The sections were counterstained with Meyer's hematoxylin (Muto Pure Chemicals, Tokyo, Japan).

All sections were scored semi-quantitatively and qualitatively, without knowledge of the clinical data. Expression levels were measured by immunohistochemical analysis on the basis 


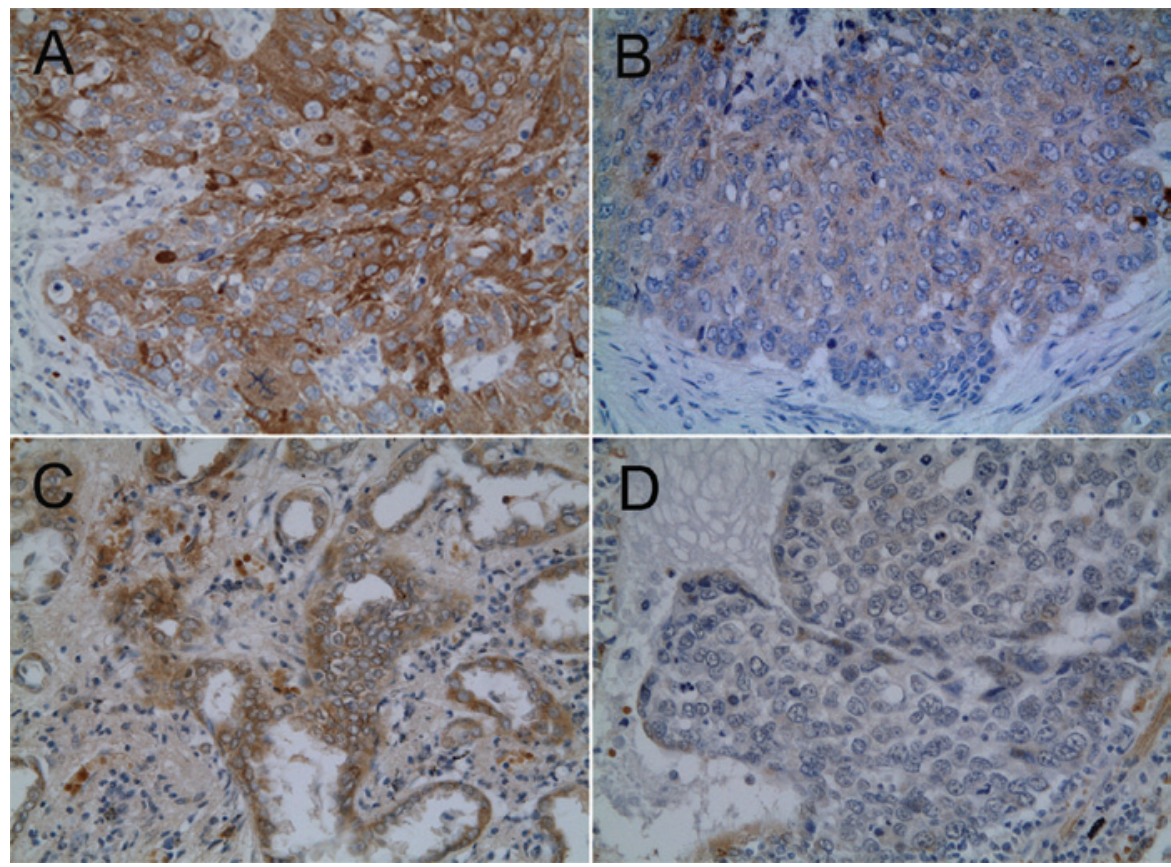

Figure 1. Immunostaining of NSCLC in serial sections. (A) Strong staining (intensity 4) of IGF-1R, and (B) weak staining (intensity 2) of IGF-1R. (C) Strong staining (intensity 4) of MMP-7, and (D) weak staining (intensity 2) of MMP-7.

of staining intensity, scored from 0 to 4 as follows: 0 , negative; 1, trace; 2 , weak; 3 , moderate; and 4, strong. The percentage of stained cells $(0-100 \%)$ was multiplied by the staining intensity (0-4). The final score ranged from 0 to 400. Staining of the sample was considered high when the score was equal to the median value or higher, or was otherwise considered as low.

Statistical analysis. Univariate analysis was performed by the $\chi^{2}$ test and Mann-Whitney U test. Continuous data were compared using the Student's t-test. The postoperative survival rate was analyzed by the Kaplan-Meier method, and differences in survival rates were assessed with the log-rank test. A Cox proportional hazard regression model was used for multivariate analyses. Death from any cause was included in the calculation of postoperative survival. Differences were considered significant at $\mathrm{P}<0.05$. All statistical manipulations were performed using the SPSS version 17.0 for Windows (SPSS Inc., Chicago, IL, USA).

\section{Results}

Expression of IGF-1R and MMP-7 according to immunohistochemical analysis. Immunohistochemical expression of IGF-1R was detected in the tumor cell membrane. Staining for MMP-7 was characterized by a heterogeneous cytoplasmic pattern (Fig. 1). Among the 78 carcinomas studied, median expression scores were 210 for IGF-1R and 140 for MMP-7. A total of $41(52.6 \%)$ carcinomas were classified as IGF-1R-high, and $42(53.8 \%)$ were classified as MMP-7-high.

Relation between expression of IGF-1R and MMP-7 and clinicopathological factors. High expression of IGF-1R was related to lymph node metastasis $(\mathrm{P}=0.034)$ and recurrence $(\mathrm{P}=0.006)$. MMP-7 expression status did not significantly correlate with any clinicopathological factor (Table II). There was no signifi- cant correlation between the expression of IGF-1R and that of MMP-7 (P=0.184).

Relation between expression of IGF-1R and MMP-7 and overall survival. Overall survival was significantly worse in patients with IGF-1R-high tumors than in those with IGF-1R-low tumors ( $\mathrm{P}=0.011)$ (Table III, Fig. 2). The 5-year survival rate was $34.1 \%$ in patients with IGF-1R-high tumors, as compared to $63.0 \%$ in those with IGF-1R-low tumors. Overall survival was slightly, but not significantly, worse in patients with MMP-7-high tumors than in those with MMP-7-low tumors. The 5-year survival rate was $37.5 \%$ in patients with MMP-7high tumors, as compared to $58.3 \%$ in those with MMP-7-low tumors $(\mathrm{P}=0.220)$ (Fig. 2). Subsequently, we conducted subset analyses to investigate the prognostic significance of IGF-1R and MMP-7. IGF-1R-high was associated with worse overall survival than IGF-1R-low in patients who were male and in those with adenocarcinoma $(\mathrm{P}=0.022$ and 0.016 , respectively) (Table IV).

Multivariate analysis of overall survival in patients with NSCLC included the following factors: IGF-1R expression, T-factor, $\mathrm{N}$-factor, gender and MMP-7 expression. Male gender ( $\mathrm{HR}=2.598 ; 95 \%$ CI 1.198-5.638, $\mathrm{P}=0.016)$, T2-4 disease $(\mathrm{HR}=2.540 ; 95 \% \mathrm{CI} 1.291-4.997, \mathrm{P}=0.007)$ and high expression of IGF-1R $(\mathrm{HR}=2.322 ; 95 \% \mathrm{CI} 1.215-4.436, \mathrm{P}=0.011)$ were significantly associated with worse overall survival (Table V).

\section{Discussion}

Overexpression of IGF-1R has been reported to promote tumor growth, invasion and metastasis in several types of malignancies (6). Despite previous studies, however, the clinical significance of IGF-1R expression in NSCLC remains unclear. MMP-7 has been reported to have multiple biologic functions related to tumor behavior, such as growth, invasion, 
Table II. Characteristics of the NSCLC patients and IGF-1R and MMP-7 expression.

\begin{tabular}{|c|c|c|c|c|c|c|}
\hline & \multicolumn{3}{|c|}{ IGF-1R expression } & \multicolumn{3}{|c|}{ MMP-7 expression } \\
\hline & High & Low & P-value & High & Low & P-value \\
\hline No. of patients & 41 & 37 & & 42 & 36 & \\
\hline Age (mean \pm SD) & $64.8 \pm 10.0$ & $64.7 \pm 11.7$ & 0.960 & $65.3 \pm 10.0$ & $64.3 \pm 11.5$ & 0.687 \\
\hline \multicolumn{7}{|l|}{ Gender } \\
\hline Male & 27 & 27 & 0.496 & 27 & 27 & 0.307 \\
\hline Female & 14 & 10 & & 15 & 9 & \\
\hline \multicolumn{7}{|l|}{ Histological type } \\
\hline Adenocarcinoma & 21 & 24 & 0.466 & 23 & 22 & 0.945 \\
\hline Squamous cell carcinoma & 17 & 9 & & 15 & 11 & \\
\hline Large-cell carcinoma & 2 & 3 & & 3 & 2 & \\
\hline Other & 1 & 1 & & 1 & 1 & \\
\hline \multicolumn{7}{|l|}{ Smoking status } \\
\hline Smoker & 29 & 27 & 0.826 & 28 & 28 & 0.277 \\
\hline Non-smoker & 12 & 10 & & 14 & 8 & \\
\hline \multicolumn{7}{|l|}{ T-factor } \\
\hline $\mathrm{T} 1$ & 17 & 18 & 0.321 & 19 & 16 & 0.986 \\
\hline $\mathrm{T} 2$ & 17 & 12 & & 15 & 14 & \\
\hline T3 & 3 & 6 & & 5 & 4 & \\
\hline $\mathrm{T} 4$ & 4 & 1 & & 3 & 2 & \\
\hline \multicolumn{7}{|l|}{$\mathrm{N}$-factor } \\
\hline No & 14 & 24 & 0.034 & 21 & 17 & 0.788 \\
\hline N1 & 6 & 5 & & 6 & 5 & \\
\hline $\mathrm{N} 2$ & 20 & 8 & & 14 & 14 & \\
\hline N3 & 1 & 0 & & 1 & 0 & \\
\hline \multicolumn{7}{|l|}{ Recurrence } \\
\hline$(+)$ & 25 & 11 & 0.006 & 19 & 17 & 0.861 \\
\hline$(-)$ & 16 & 26 & & 23 & 19 & \\
\hline
\end{tabular}
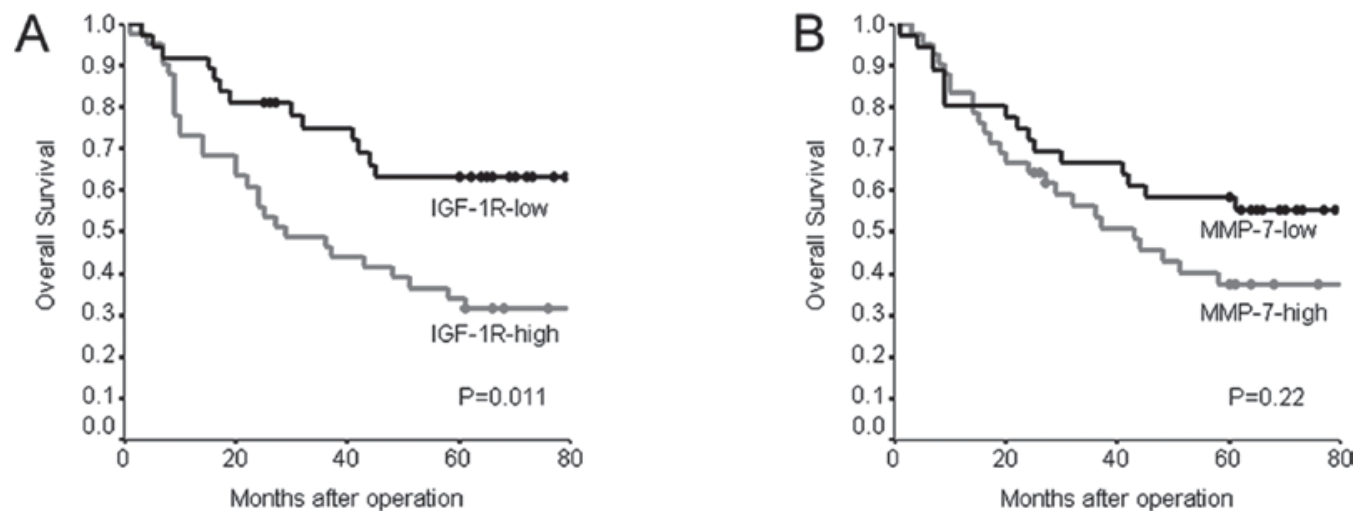

Figure 2. Overall survival of 78 patients with NSCLC. (A) IGF-1R-high vs. IGF-1R-low NSCLC; (B) MMP-7-high vs. MMP-7-low NSCLC.

proliferation and apoptosis. In addition, a relation between MMP-7 expression and postoperative outcomes has been reported (12-14), but definitive evidence is lacking. Therefore, we studied immunohistochemically the expression of IGF-1R and MMP-7 in post-surgical patients with NSCLC.

We assessed the association of IGF-1R and MMP-7 expression with clinicopathological features. Dziadziuszko et al (17) found that IGF-1R expression was higher in squamous cell carcinomas than in other histological types and was associated with disease stage. Cappuzzo et al (18) reported that a positive IGF-1R expression was significantly associated with squamous cell histology and grade III differentiation. Ludovini et al (19) reported that IGF-1R protein overexpression was associated with larger tumor size. Merrick et al (20) showed that higher IGF-1R scores were associated with adenocarcinoma and never-smokers. Our results showed that high IGF-1R expres- 
Table III. Univariate analysis of overall survival in NSCLC.

\begin{tabular}{lcc}
\hline Variables & $\begin{array}{c}\text { 5-year survival } \\
\text { rate (\%) }\end{array}$ & P-value \\
\hline Gender & & 0.015 \\
Male & 40.1 & \\
Female & 64.8 & 0.176 \\
Histological type & & \\
Adenocarcinoma & 54.2 & 0.002 \\
Squamous cell carcinoma & 37.5 & \\
T-factor & & 0.280 \\
T1 & 67.2 & \\
T2,3,4 & 32.5 & 0.109 \\
N-factor & & \\
N0 & 57.2 & \\
N1,2,3 & 38.9 & 0.220 \\
Smoking status & & \\
Smoker & 43.6 & \\
Non-smoker & 57.7 & \\
IGF-1R expression & & \\
High & 34.1 & \\
Low & 63.0 & \\
MMP-7 expression & & \\
High & 58.3 & \\
Low & & \\
\hline
\end{tabular}

sion was significantly related to higher $\mathrm{N}$-factor $(\mathrm{P}=0.034)$ and recurrence $(\mathrm{P}=0.006)$. As for histological type, IGF-1R expression was slightly, but not significantly, higher in squamous cell carcinomas.

Concerning MMP-7 expression, Liu et al (12) showed that MMP-7 expression was significantly higher in squamous cell carcinomas than in adenocarcinomas. Leinonen et al (13) reported that high MMP-7 expression was related to lower T-factor and well-differentiated tumors; moreover, MMP-7 expression was higher in adenocarcinomas than in other histological subtypes. Sasaki et al (14) demonstrated a trend toward higher MMP-7 mRNA expression levels in NSCLCs with lymph node metastasis. By contrast, our results showed no correlation between MMP-7 and any clinicopathological factor.

We also analyzed the relationship of IGF-1R and MMP-7 expression to post-surgical outcomes. Previously, Merrick et al (20) analyzed IGF-1R expression in 184 surgically treated patients with stage I to IV NSCLC. In stage I disease, high IGF-1R expression was associated with significantly shorter survival than low IGF-1R expression. Dziadziuszko et al (17) evaluated 189 NSCLCs and showed that the $I G F-1 R$ gene copy number is of prognostic value; nonetheless, IGF-1R protein expression upon immunohistochemical analysis was not related to survival. Ludovini et al (19) reported that IGF-1R protein expression alone was not significantly associated with survival, although high co-expression of both IGF-1R and epidermal growth factor receptor was associated with shorter

Table IV. Subset analysis of overall survival in NSCLC.

\begin{tabular}{|c|c|c|c|c|c|c|}
\hline \multirow[b]{2}{*}{ Variables } & \multicolumn{6}{|c|}{ 5-year survival rate $(\%)$} \\
\hline & IGF-1R-high & IGF-1R-low & P-value & MMP-7-high & MMP-7-low & P-value \\
\hline \multicolumn{7}{|l|}{ Gender } \\
\hline Male & 25.9 & 54.5 & 0.022 & 24.0 & 55.5 & 0.051 \\
\hline Female & 50.0 & 87.5 & 0.064 & 62.2 & 66.6 & 0.955 \\
\hline \multicolumn{7}{|l|}{ Histological type } \\
\hline Adenocarcinoma & 38.1 & 68.4 & 0.016 & 48.9 & 59.0 & 0.608 \\
\hline Squamous cell carcinoma & 29.4 & 55.5 & 0.586 & 23.3 & 54.5 & 0.478 \\
\hline \multicolumn{7}{|l|}{ Pathological stage } \\
\hline I & 53.8 & 72.8 & 0.182 & 61.1 & 71.4 & 0.601 \\
\hline II, III & 25.0 & 53.5 & 0.072 & 22.2 & 50.0 & 0.246 \\
\hline \multicolumn{7}{|l|}{ Smoking status } \\
\hline Smoker & 31.0 & 57.6 & 0.050 & 28.8 & 57.1 & 0.104 \\
\hline Non-smoker & 41.6 & 77.7 & 0.087 & 54.5 & 62.5 & 0.913 \\
\hline
\end{tabular}

Table V. Multivariate analysis of overall survival in NSCLC.

\begin{tabular}{lccc}
\hline Variables & P-value & Hazard ratio & 95\% confidence interval \\
\hline Gender & 0.016 & 2.598 & $1.198-5.638$ \\
T-factor & 0.007 & 2.540 & $1.291-4.997$ \\
IGF-1R & 0.011 & 2.322 & $1.215-4.436$ \\
\hline
\end{tabular}


disease-free survival in resected NSCLC. Cappuzzo et al (18) concluded that IGF-1R expression does not represent a prognostic factor in resected NSCLC patients.

In the present study, overall survival was significantly poorer in patients with IGF-1R-high tumors than in those with IGF-1R-low tumors, and multivariate analysis showed IGF-1R expression as an independent indicator of poor outcomes. As for MMP-7, Liu et al (12) reported that the overall survival rate was significantly lower in patients with MMP-7-positive NSCLC than in those with MMP-7-negative NSCLC. On the other hand, Leinonen et al (13) reported that MMP-7 had no prognostic value in NSCLC. Our results showed a trend toward poorer survival in patients with MMP-7-high tumors than in those with MMP-7-low, but the difference fell short of reaching statistical significance.

In conclusion, our results suggest that overexpression of IGF-1R is a useful predictor of lymph node metastasis and recurrence in patients with NSCLC. Overexpression of IGF-1R may thus be an important prognostic factor along with gender and T-factor in patients with NSCLCs.

\section{References}

1. Dufourny B, Alblas J, van Teeffelen HA, et al: Mitogenic signaling of insulin-like growth factor I in MCF-7 human breast cancer cells requires phosphatidylinositol 3-kinase and is independent of mitogen-activated protein kinase. J Biol Chem 272: 31163-31171, 1997

2. Khandwala HM, McCutcheon IE, Flyvbjerg A and Friend KE: The effects of insulin-like growth factors on tumorigenesis and neoplastic growth. Endocr Rev 21: 215-244, 2000.

3. Baserga R, Hongo A, Rubini M, Prisco M and Valentinis B: The IGF-I receptor in cell growth, transformation and apoptosis. Biochim Biophys Acta 1332: F105-F126, 1997.

4. Blakesley VA, Stannard BS, Kalebic T, Helman LJ and LeRoith D: Role of the IGF-I receptor in mutagenesis and tumor promotion. J Endocrinol 152: 339-344, 1997.

5. LeRoith D and Roberts CT Jr: The insulin-like growth factor system and cancer. Cancer Lett 195: 127-137, 2003.

6. Turner BC, Haffty BG, Narayanan L, et al: Insulin-like growth factor-I receptor overexpression mediates cellular radioresistance and local breast cancer recurrence after lumpectomy and radiation. Cancer Res 57: 3079-3083, 1997.

7. Long L, Rubin R and Brodt P: Enhanced invasion and liver colonization by lung carcinoma cells overexpressing the type 1 insulin-like growth factor receptor. Exp Cell Res 238: 116-121, 1998.
8. Visse $\mathrm{R}$ and Nagase $\mathrm{H}$ : Matrix metalloproteinases and tissue inhibitors of metalloproteinases: structure, function, and biochemistry. Circ Res 92: 827-839, 2003.

9. Mott JD and Werb Z: Regulation of matrix biology by matrix metalloproteinases. Curr Opin Cell Biol 16: 558-564, 2004.

10. Miyata Y, Iwata T, Ohba K, Kanda S, Nishikido M and Kanetake H: Expression of matrix metalloproteinase-7 on cancer cells and tissue endothelial cells in renal cell carcinoma: prognostic implications and clinical significance for invasion and metastasis. Clin Cancer Res 12: 6998-7003, 2006.

11. Kitoh T, Yanai H, Saitoh Y, et al: Increased expression of matrix metalloproteinase-7 in invasive early gastric cancer. J Gastroenterol 39: 434-440, 2004.

12. Liu D, Nakano J, Ishikawa S, et al: Overexpression of matrix metalloproteinase-7 (MMP-7) correlates with tumor proliferation, and a poor prognosis in non-small cell lung cancer. Lung Cancer 58: 384-391, 2007.

13. Leinonen T, Pirinen R, Bohm J, Johansson R, Ropponen K and Kosma VM: Expression of matrix metalloproteinases 7 and 9 in non-small cell lung cancer. Relation to clinicopathological factors, beta-catenin and prognosis. Lung Cancer 51: 313-321, 2006.

14. Sasaki H, Yukiue H, Moiriyama S, et al: Clinical significance of matrix metalloproteinase-7 and Ets-1 gene expression in patients with lung cancer. J Surg Res 101: 242-247, 2001.

15. Miyamoto S, Yano K, Sugimoto S, et al: Matrix metalloproteinase-7 facilitates insulin-like growth factor bioavailability through its proteinase activity on insulin-like growth factor binding protein 3. Cancer Res 64: 665-671, 2004

16. Adachi Y, Li R, Yamamoto H, et al: Insulin-like growth factor-I receptor blockade reduces the invasiveness of gastrointestinal cancers via blocking production of matrilysin. Carcinogenesis 30: 1305-1313, 2009.

17. Dziadziuszko R, Merrick DT, Witta SE, et al: Insulin-like growth factor receptor 1 (IGF1R) gene copy number is associated with survival in operable non-small-cell lung cancer: a comparison between IGF1R fluorescent in situ hybridization, protein expression, and mRNA expression. J Clin Oncol 28: 2174-2180, 2010.

18. Cappuzzo F, Tallini G, Finocchiaro G, et al: Insulin-like growth factor receptor 1 (IGF1R) expression and survival in surgically resected non-small-cell lung cancer (NSCLC) patients. Ann Oncol 21: 562-567, 2010.

19. Ludovini V, Bellezza G, Pistola L, et al: High coexpression of both insulin-like growth factor receptor-1 (IGFR-1) and epidermal growth factor receptor (EGFR) is associated with shorter disease-free survival in resected non-small-cell lung cancer patients. Ann Oncol 20: 842-849, 2009.

20. Merrick DT, Dziadziuszko R and Szostakiewicz B: High insulinlike growth factor 1 receptor (IGF1R) expression is associated with poor survival in surgically resected non-small cell lung cancer (NSCLC) patients (pts). J Clin Oncol 25 (Suppl): 7550, 2007. 